\title{
A percepção da mulher sobre o exame preventivo do câncer cérvico-uterino: estudo de caso
}

\author{
Women's perceptions of preventive examinations \\ for cervical-uterine cancer: a case study
}

\author{
Lucélia M aria Duavy ${ }^{1}$ \\ Fátima Lucia Ramos Batista ${ }^{1}$ \\ M aria Salete Bessa J orge ${ }^{2}$ \\ João Bosco Feitosa dos Santos ${ }^{2}$
}

\footnotetext{
Secretaria M unicipal de Saúde de Fortaleza. Hospital Distrital Gonzaga M ota JoséWalter.

Avenida D 440/2a et, José Walter. 60.750-030 Fortaleza CE.

Iduavy@yahoo.com.br

2 Universidade Estadual do
}

Abstract Cervical-uterine cancer is among the most feared chronic degenerative diseases, due its high mortality and morbidity rates. This study describes women's feelings before a preventive examination for cervical-uterine cancer, through a case study based on observations and semi-structured interviews as data collection techniques. A total of 24 women were interviewed, between eighteen and sixty years old, who attended the cancer prevention unit at a basic healthcare clinic in Fortaleza, Ceará State between April and August 2004. This study shows that women generally request these preventive examinations only when symptoms appear. They view this procedure with apprehension and fear, due to the possibility of a positive diagnosis of cervical-uterine cancer; they feel embarrassed at exposing their bodies for examination, particularly by male physicians; and they are poorly informed about their own bodies and even their own sexuality. Thesefindingshighlight the need for healthcare practitioners to conduct educational activities for women, in order to enhance professional relationships between healthcare providers and users, helping lower the rate of this type of cancer through more frequent preventive examinations.

Key words Perception, Preventive examination, Cervical-uterine cancer, Case study
Resumo 0 câncer cérvico-uterino éuma das doenças crônico-degenerativas mais temidas, em razão do seu alto grau de letalidade e morbidade. N esse sentido, realizamos um estudo para descrever a percepção das mulheres ante o exame de prevenção de câncer cérvi co-uterino. O ptamos por um estudo de caso tendo a observação e a entrevista semi-estruturada como técnicas de coleta das informações. Foram entrevistadas vinte e quatro mulheres, entre 18 e 60 anos, que buscaram o serviço de prevenção em uma unidade básica de saúde deFortaleza-CE, entreabril eagosto de2004. 0 estudo revelou que a mulher geralmente só procura fazer o exame de preven ção quando surgem sintomas, por ter vivenciado este exame com apreensão e medo pela possibilidade de um diagnóstico positivo de um câncer cérvico-uterino; sente-se constrangi da em expor seu corpo e têlo examinado, sobretudo, quando o profissional de saúde édo sexo masculino; não tem conhecimento do corpo e tampouco desua sexualidade. Esseresultado aponta para a necessidade de o profissional de saúde de senvolver atividades educativas junto às mulheres, no sentido de melhorar a relação profissional de saúde-usuária e, conseqüentemente, diminuir a incidência deste tipo de câncer, pela maior fre qüência aos exames de prevenção.

Palavras-chave Percepção, Exame de prevenção, Câncer cérvico-uterino, Estudo de caso 


\section{Introdução}

0 câncer cérvico-uterino éa doença crônico-degenerativa mais temida, em virtude do seu alto grau de letalidade e morbidade, apresentando possi bilidade de cura se for diagnosticada precocemente. Ainda éum problema de saúde pública em países em desenvolvimento, pois alcança altas taxas de prevalência e mortalidade em muIheres de estratos sociais e econômicos mais baixos e que se encontram em plena fase produtiva. A evolução do câncer de colo uterino, na maioria doscasos, acontece de forma lenta, passando por fases pré clínicas detectáveis e curáveis. Dentre todos os tipos de câncer, é o que apresenta um dos mais altos potenciais de cura pela prevenção. A incidência desse tipo de câncer ocorre na faixa etária de 20 a 29 anos eo risco aumenta à medida que se atinge a faixa etária de 45 a 49 anos. $\mathrm{Na}$ América Latina eno SudesteA siático, as taxas de incidência são geralmente altas, enquanto na América do Norte, Austrália, norte e oeste europeus são consideradas baixas ${ }^{1}$.

Estudos revelam consistente associação entre o câncer cérvico-uterino eo baixo nível socioeconômico em todas as regiões do mundo. Os grupos vulneráveis concentram-se onde existem as maiores barreiras de acesso à rede de serviços, para detecção e tratamento precoce da patologia e de suas lesões precursoras, advindas de dificuldades econômicas e geográficas, insuficiência de serviços e por questões culturais, como medo e preconceito dos companheiros.

0 câncer cérvico-uterino figura como a terceira neoplasia maligna mais comum, sendo superado apenas pelo câncer de pele (não-melanoma) e pelo câncer de mama. Os últimos dados colhidos no INCA/M S2, sobre mortalidade por câncer, revelam que, no Brasil, em 2000, a modalidade cérvico-uterina levou a óbito 3.953 mulheres, fato este que pode ser atribuído à baixa cobertura da citologia oncótica.

A rede básica de saúde em Fortaleza foi responsável, em 2003, por uma cobertura da citologia oncótica em $59,4 \%$. Até 0 ano de 2001 , os exames citopatológicos eram gerados e monitorados manualmente, apesar de o Sistema de Informação da Prevenção de Câncer do Colo U terino ter sido implantado em 2000. Em 2002, 0 M inistério da Saúde desencadeou a segunda fase de intensificação da coleta dos exames, com destaque para a busca ativa das mulheres com neoplasia intra-epitelial cervical (NIC) e vírus papiloma humano (HPV), fato que contribuiu para a organização da rede na oferta desses serviços ${ }^{3}$.
Em 2005, foi estimado para o Estado do Ceará a ocorrência de 770 casos novos, com uma taxa bruta de incidência de 18,70 por 100.000 , enquanto em Fortaleza foram esperados $260 \mathrm{ca}$ sosnovos euma taxa bruta deincidência de 20,64 por 100.000 .

Tomamos como ponto de partida o PAISM , por entendermos que existem ações desenvolvidas na perspectiva de melhorar o índice de morbi-mortalidade por câncer cérvico-uterino. Surgiu o Programa, em 1983, a partir da convergência das propostas oriundas dos movimentos feminista e sanitário brasileiro, como nova e diferenciada abordagem da saúde da mulher, com base no conceito de "atenção integral à saúde das mulheres" ${ }^{4,5,6}$. Para o movimento das mulheres, o conceito de "integral" deveria enfatizar, não somente, a integração do colo do útero e das mamas, mas referir-se também ao contexto social, psicológico e emocional das mulheres a serem atendidas. Além disso, os movimentos de muIheresinsistiram na inclusão, entreoutras, deações definidas de educação sexual e em saúde, para afastar qualquer possibilidade de o programa ser usado para o controle populacional coercitivo?.

O PAISM veio constituir um conjunto de princípios e diretrizes destinados a orientar toda a assistência ofertada às mulheres, nas suas necessidades e demandas específicas, não somente do processo reprodutivo, mas voltadas à promoção da saúde das mulheres e não apenas à saúde de seus filhos. Para Formiga', é uma das mais importantes políticas públicas na área da saúde, por estabelecer em suas linhas de ação e estraté gias, um modelo assistencial integral e eqüitativo. Em seu arcabouço, eram pautadas ações educativas, preventivas, de diagnóstico, tratamento e recuperação, englobando a assistência à muIher em clínica ginecológica, no pré-natal, parto e puerpério, no climatério, em planejamento familiar, DST, câncer de colo uterino e de mama, além de outras necessidades identificadas a partir do perfil populacional das mulheres. As diretrizes gerais do PAISM estabeleciam, também, a exigência de uma nova atitude de trabalho da equipe de saúde, em face do conceito de integralidade na atenção, além de pressupor uma prática educativa permeando todas as atividades a serem desenvolvidas, de forma que a clientela pudesse apropriar-se dos conhecimentos necessários a um maior controle sobre sua saúde?.

Embora o PAISM englobasse ações direcionadas a todas as fases da vida da mulher, na prática, essas ações foram trabal hadas na perspectiva de solução de problemas, priorizando-se a 
saúde reprodutiva e, particularmente, as ações para redução da mortalidade materna (prénatal, assistência ao parto e anticoncepção) ${ }^{10}$. Para esses autores, embora se tenha mantido como foco a atenção integral à saúde da mulher, essa definição de prioridades dificultou a atuação de outras áreas estratégicas do ponto de vista do leque de ações da saúde da mulher. Essa perspectiva deatuação também comprometeu a transversalidade de gênero e etnia, apesar de se notar avanços no sentido da integralidade e no processo de ruptura das ações verticalizadas do passado, uma vez que outras questões da vida da muIher foram sendo incorporadas, a exemplo, a violênciasexual.

A despeito disso, em 2003, a Área Técnica da Saúde da Mulher do M inistério da Saúde formula a Política Nacional deAtenção I ntegral à Saúde da Mulher, recuperando a ótica dos princípios da eqüidade e da integralidade contidos no PAISM. Redefine diretrizes para atenção e um plano deação norteado pela perspectiva de gênero, considerando os recortes racial-étnicos. Contempla as mulheres em todos os ciclos da vida, resguardando as especificidades das diferentes faixas etárias e dos variados grupos populacionais, propondo a formulação de um modelo de atenção humanizado e com qualidade, capaz de responder às necessidades das mulheres atendidas no SUS ${ }^{11}$

É nesse contexto que realizamos este estudo, com o objetivo de compreender a percepção da mulher diante da realização do exame deprevenção de câncer cérvico-uterino.

\section{Caminho metodológico}

O ptamos pela realização de um estudo de caso ${ }^{12}$ em uma unidade básica de saúde que compõe a rededeserviços da Secretaria M unicipal deSaúde de Fortaleza (SM S), no período de abril a agosto de 2004, utilizando como técnicas de coleta de dados entrevistas semi-estruturadas gravadas ${ }^{13}$ e observação livre.

A pesquisa foi desenvolvida no momento em que obtivemos aprovação do projeto pelo Comitê de Ética da Universidade Estadual do Ceará (UECE), com a concordância da gerência do Distrito de Saúde da Secretaria Executiva Regional VI e da gerência do serviço.

Para delimitar a suficiência dos dados, utilizamos 0 critério de saturaçãa ${ }^{14}$. As entrevistas, em número de vinte e quatro, foram realizadas com mulheres com idade entre 18 e 60 anos, no serviço de saúde, logo após o término do exame de prevenção. A observação livre foi utilizada como técnica complementar para captar informações sobre o contexto dos serviços que envolvem o exame de prevenção e registradas em diário de campo. Pode-se observar maior fluxo de pessoas, para esse exame, no período da manhã.

0 critério de seleção das entrevistadas foi tão somente $o$ fato de estarem naquele local para re alizar o exame, entretanto, o grupo de informantes foi constituído a partir do desejo de participar do estudo.

A questão norteadora do estudo foi: "Você poderia mefalar o que representa a realização do exame de prevenção decâncer para sua vida?" As entrevistas foram gravadas em fitas cassete, com autorização prévia das depoentes, mediante assinatura do Termo de Consentimento Livre e Esclarecido, elaborado segundo Resolução № 196, de 10/10/1996, do Conselho Nacional deSaúde ${ }^{15}$. 0 anonimato das mulheres foi garantido a partir da adoção de nomes fictícios nas citações de seus discursos.

Para tratamento do material, utilizamos a técnica deanálise de conteúdo, do tipo categorial temática proposta por Bardin ${ }^{16}$. Com as leituras das entrevistas e das descrições das observações, recorte de trechos de falas, escolha das unidades de registro (frase), unidade de contexto (parágrafo), elaboramos os núcleos de sentido: Cuidando da saúde; Corpo e sexualidade; Periodicidade do exame; Expressando sentimentos; Acessibilidade ao serviço; e Desinformação sobre o exame.

\section{Núcleos desentidos: prevenção do câncer do cérvico-uterino na percepção da mulher}

\section{Cuidando da saúde}

As mulheres percebem o exame de prevenção como uma forma de se cuidar. Em suas falas, demonstraram preocupação e interesse em saber suas condições de saúde. A pesar de reconhecer, no entanto, a importância da prevenção e preservação da saúde como possibilidade de uma vida saudável, algumas mulheres buscaram assistência a partir do aparecimento de sintomas: [...] Já tá na hora de marcar uns exames para fazer a prevenção, pra saber o queéessas dores no pé-dabarriga. (Francis, 26 anos).

Segundo Rodrigues et al. ${ }^{17}$, a mulher também é motivada à realização do exame pela presença 
de supostos fatores de risco, tais como hereditariedade e relações extraconjugais, esteúltimo fator implícito na falta de confiança que as mulheres têm em relação ao seu companheiro. Esta opinião foi reforçada quando falaram que realizaram a prevenção pela incerteza quanto à fidelidade do companheiro. Como exemplo: [...] Às vezes a pessoa pega, né! Porque ninguém conheceo homem, e outra coisa, a gente tem que se prevenir. (Lucy, 38 anos). Além dos fatores predisponentes a estetipo de câncer, estudos epidemiológicos sugerem outros, como tabagismo, alimentação pobre em alguns micronutrientes (vitamina $\mathrm{C}$, betacaroteno e folato) e uso de anticoncepcionais, cujo papel ainda não é conclusivo ${ }^{1}$.

A consciência de quea realização do exameé uma forma de cuidar dos órgãos genitais foi evidenciada na fala: Porque a gente quer saber o que está acontecendo com o organismo da pessoa, né? Que o útero é um organismo da gente, muito importante! Aí eu fico[...] Pensando assim[...] Eu quero fazer a minha prevenção. Eu quero saber se estou bem mesmo. (M aria, 40 anos).

$\mathrm{N}$ as narrativas, apreendemos a noção de que a mulher busca assistência médica ao identificar problemas em si mesma eque apreen de o câncer ginecológico como algo temível e ameaçador, do qual pode ser vitimada. $\mathrm{Na}$ busca por assistência, a mulher demonstra preocupação com o "cuidar de si". 0 ato de cuidar da saúde deve ser entendido como algo intrínseco do ser humano, pois se o ser humano ao longo da vida não fizer com cuidado todos os seus empreendimentos, prejudicaráa si mesmo edestruirá o que estiver à sua volta, pois sem cuidado o ser humano deixa de ser humano ${ }^{18}$, principalmente no momento em que há descuido e descaso em relação à vida das pessoas e de si mesmo ${ }^{19}$.

\section{Corpo e sexualidade}

Ao tratar do exame ginecológico, junto às mulheres, não foi possível desconsiderar a sexualidade. A sexualidade refere-se ao impulso e à emoção quea proximidade do sexo pode produzir, transcendendo definições físicas ese colocando como algo mais difuso que permeia todos os momentos da vida ${ }^{20}$. Assim, as experiências particulares de homens e mulheres no tocante à sexualidade eà reprodução só podem ser consideradas à luz das diferenças de gênero que conformam as representações e práticas masculinas e femininas em cada cultura ${ }^{21}$.

A sexualidade, como manifestação biopsicossocial do ser humano, foi objeto através da his- tória, de toda a sorte de controle por interesses diversos. Negada ou incentivada, a Igreja, o Estado e o poder econômico sempre se valeram deste meio profundo do relacionamento humano (em que a afetividade e o prazer formam a base motivacional), para dominar, corromper, atemorizar ou mesmo lucrar ${ }^{22}$.

Ao estudar as estratégias em relação à sexualidade a partir do século XVII, Foucalt ${ }^{23}$ descreve: Toda essa atenção loquaz com quenos alvoroçamos em torno da sexualidade, há dois ou três séculos, não estaria ordenado em função de uma preocupação elementar: assegurar o povoamento, reproduzir a força de trabalho, reproduzir as formas das relações sociais, em suma, proporcionar uma sexualidade útil e politicamente conservadora.

A forma como algumas mulheres se manifestaram ao terem que expor seu corpo, têlo manipulado e examinado por um profissional, revela o quanto a sexualidade tem influência sobre a vida da mulher; afinal, trata-se de tocar, manusear órgãos e zonas erógenas. Daí talvez 0 fato de as mulheres associarem sempre a exposição das genitálias à sexualidade, produzindo sentimento de vergonha em relação às suas partes. Nesse sentido, trabal har com a sexualidade é lidar com um tema especial, abrangentee complexo, pois, mesmo com vasta bibliografia, envolve questões não comumente abordadas com liberdade pelas pessoas.

Analisando as entrevistas, observamos o fato de a sexualidade ainda ser superficialmente discutida ou não debatida nas diversas fases da vida, constituindo-se um bloqueio, conflito este presente em todos os depoimentos, levando grande parte das mulheres a sentirem-se envergonhadas e constrangidas, em virtude da exposição do corpo - [...] ela [a médica] mandou eu tirar a roupa queela ia e depois voltava. Ai, aí eu entrava dentro do banheiro e saía, morrendo de vergonha, né? Eu tirava a blusa evestia denovo, tanta vergonha. Aí [...] Ela [a médica] entrou eeu ainda não tinha tirado a roupa [...] Ela [a médica] memandou[...] Tirar a roupa que não fazia vergonha não, [...] aí eu entrei e tirei a roupa morrendo de vergonha[...] Aí depois deitei na mesa, aí fez lá [...] [o exame]. (Iracy, 32 anos).

Algumas depoentes aproveitaram a entrevista para falar de seus relacionamentos e de sua vida sexual. Em seus depoimentos, percebemos que existe uma mistificação estética do sexo, que torna quase impensável, ou mesmo imoral, inadequada ou antiestética a reivindicação de prazer por uma mulher comum, explicitada na revelação de uma mulher aos sessenta anos de idade: 
$\mathrm{N}$ ão tenho vontade de fazer sexo de jeito nenhum, eu não tenho vontade. É como quemorri [...] Não sinto mais nada por ele, perdi o amor pelo meu esposo[...] traumatizada com isso, tenho muito sofrimento [...] [chorou]. Falei para o médico, aí ele me encaminhou para fazer um tratamento no [...] CAPS [Centro de Atenção Psicossocial]. (Dadá, 61 anos). O sexo é uma dimensão importante da relação do indivíduo consigo mesmo e com outro, e ainda, fator decisivo para a harmonia conjugal. Laplanche ${ }^{24}$ exprime a idéia de que sexualidade não designa apenas as atividades e o prazer que dependem do funcionamento do aparel ho genital, mas de toda uma série de excitações e de atividades presentes desde a infância, que proporcionam um prazer irredutível à satisfação de uma necessidade fisiológica fundamental e que se encontram a título de componentes na chamada forma normal do amor sexual. 0 sofrimento retratado por uma mulher, ao se considerar "morta" para a vida, em conseqüência da falta de amor por seu cônjuge, nos remete à suposta diminuição do desejo sexual feminino, queintegra o conjunto de imagens públicas da menopausa e do envel hecimento, que parecem reificados pela Biomedicina ${ }^{25}$. Essa situação podeser reforçada pela exploração comercial da sexualidade feminina, nos dias dehoje, que oferece uma idéi superficial, desvinculada do afeto, sustentada em modelos descartáveis, consumistas, estereotipados e preconceituosos, com a imposição da estética e como prerrogativa exclusiva dajuventude ${ }^{22}$. Além do mais, Freud ${ }^{26}$, em seu estudo sobre a sexualidade, no século XX, já mostrava a centralidade do sexo em todosos aspectos do desenvolvimento humano, observando, ainda, que as experiências e condutas sexuais infantis contribuem para a vida e para a conduta da pessoa adulta de um modo vasto e abrangente.

O utro aspecto emergente no discurso de D adá refere-seà forma inci piente de como questões relacionadas à sexualidade são tratadas por profissionais de saúde. A incorporação da sexualidade às práticas de saúde ainda é complexa, uma vez que a maioria das mulheres sente dificuldade em abordar esse assunto e, por outro lado, depara-se com a ineficiência dos serviços de saúde em tratar essa temática.

Parafraseando Villela $a^{27}$, eventuais orientações para o exercício mais prazeroso da sexualidade mantêm-se fora dos serviços e das práticas de saúde; ao mesmo tempo em que a tarefa "educativa", necessariamente presente em toda ação de saúde, assumida como proposta ativa de ação no âmbito do PAISM fica reduzida a uma fria e assexuada orientação sobre uso de contraceptivos ou sobre realização de exames para prevenção do câncer cérvico-uterino.

A influência da cultura na educação ena conduta da família em relação à sexualidade foi também destacada por quase todas as depoentes, que mencionaram a dificuldade da mãe abordar essa questão, como também a realização do exame de prevenção. Tal afirmação nos leva à questão de gênero, pois somos educadas por mulheres, numa sociedade onde a virilidade e o prestígio do macho estão longe de serem apagados ${ }^{20}$ e, por motivos culturais, 0 sexo ainda évisto como al go ligado à reprodução e ao prazer, reprimido, por ser considerado moralmente condenável. Diamantino et al. ${ }^{28}$ são da opinião de que a mulher brasileira desde que nasce é educada "para dentro". É criada para servir, para ser obediente, casar, respeitar seu marido, ter filhos, ser dona de casa, sujeitar-se a um trabalho exaustivo, sem folgas ou reconhecimento.

As mulheres citaram o desconhecimento do exame e a própria educação que receberam cujo assunto não era discutido, como se evidencia na narrativa: A minha mãe nunca fez prevenção até hoje ela[...] Nem nada né, engravidei assim de repente[ ...] M asmesmo com vergonha[...] Eu faço. (Iracy, 32 anos).

Desses discursos, verificamos que a média idade das entrevistadas (na maioria em torno de 30 anos) não era indicativa de despudor no momento do exame. Para essas mulheres e para outrem, 0 ato de despir-se estava tão relacionado à sexualidade que, mesmo diante do profissional de saúde, seu comportamento se assemeIhava ao de suas mães e avós, já que a visão do corpo não havia sido modificada nos vários aspectos. Isso é possível, haja vista que a mulher, quando criança, foi levada a ter bons modos e controle sobresua vontade. $\mathrm{N}$ a adolescência, não é preparada para a vida, mas sim para negar 0 prazer, cheio de culpa, censura emedo. Nesta fase, asquestões sobre sexo produzem constrangimentos e são respondidas de modo incompleto, ou, quando não, são ignoradas. Certamente, conhecer a anatomia do próprio corpo ainda é um desafio para muitas mulheres, mesmo nos dias dehoje.

Ao longo da história enas diferentes sociedades, o corpo feminino é regulado por meio de normas, sejam elas baseadas em crenças, mágicas, religião ou M edicina. 


\section{Periodicidade do exame}

Outra categoria observada nos discursos é a periodicidade com que essas mulheres realizam o exame de prevenção. Das vinte e quatro entrevistadas, treze estão em dia com o exame, onze não estão e, deste contingente, há aquelas que procuram atendimento a partir desintomas, que, no caso, foram nove mulheres. Do total, quatro fizeram o exame pela primeira vez. Francise Cida, por exemplo, garantem realizar o exame anualmente, e associam a ida ao ginecologista como um ato de responsabilidade e compromisso com a sua saúde. Isto é descrito em um dos depoimentos: Considero sim o exame importante, eu tenho que fazer, porque se eu não fizer esse exame eu nunca vou saber o que eu tenho[...] Aí todos os anos eu faço. (Francis, 26 anos). Fiz exame em 2003[...] Tem mais ou menos um mês que a gente falou [com vizinha] que tava na época da gente fazer, aí ela, marcou né [...] Aí viemosjuntos hoje fazer o exame [...] (Cida, 35 anos).

Algumas mulheres que estão em dia com o exame preocupam-se, em demasia, com sua saúde. 0 cuidado chega a ser exagerado, pois queriam realizar o examea cada seismeses. N essa perspectiva, Boff ${ }^{19}$ ressalta que o cuidado deve ser entendido na linha da essência humana. Por ser o cuidado essencial, não pode ser suprimido nem descartado. Há os que têm cuidado em demasia consigo mesmo, preocupam-se demais. 0 excesso de cuidado origina a obsessão, pois impõem muito cuidado em tudo o que fazem, tornandose ato obsessivo.

No sentido deregular a periodicidade do exame Papanicolau nos programas de rastreamento do câncer cérvico-uterino, o M S/I NCA recomenda a adoção de três anos, após a obtenção de dois resultados negativos com intervalo de um ano ${ }^{2}$.

\section{Expressão de sentimentos}

\section{A vergonha}

O maior sentimento percebido no relato das mulheres que fazem o exame de prevenção de forma regular é a vergonha. A cada vez que a mulher expõe seu corpo, aflora este sentimento, que pode ser justificado pelo tabu do sexo, proveniente da educação recebi da, bem como da falta de informação. Observemos no relato a seguir: A gente que tem uma cultura tão arraigada no pudor. É uma coisa assim [...] Valha! Eu tô com vergonha. Ela tá me vendo ali, 'daquele jeito' mas [...] Depois é tudo normal. (Eva, 20 anos).
Além da vergonha de mostrar o corpo, algumasmulheres manifestaram desconforto durante a posição ginecológica, referindo-se ao fato de não se mostrarem despidas (dessa forma) nem mesmo para o marido, como seevidencia nafala: É porque é uma posição constrangedora, eu acho horrível. (Dora, 43 anos). La Taille $e^{29}$ não estabelece o lugar que a vergonha ocuparia na lista de sentimentos do homem, porém ele afirma que se trata deum sentimento demaior importância tanto para se entender o ser humano de forma geral, quanto para compreender seu juízo e comportamento morais. Darwin ${ }^{30}$ foi outro autor que se debruçou minuciosamente sobre a vergonha, ao pesquisar a expressão das emoções nos homens e nos animais, afirmando que o enrubescer é 0 mais especial e a mais humana de todas as emoções; e La Taill le ${ }^{29}$ define vergonha como um conjunto de representações de si, sendo que estas representações sempre remetem a valores e que a busca de valores positivos éuma das grandes motivações para as condutas humanas. A quantidade de palavras que se relacionam à vergonha e a riqueza de significado destas relações, por si só, depõem a favor da importância deste sentimento na vida de cada indivíduo e nas relações que mantêm com os outros membros da sociedade, conforme depoimento a seguir: Eu ficava com vergonha de ficar com as pernas abertas pro médico. (Mary, 18 anos).

Um problema essencial do sentimento devergonha é o lugar do juízo alheio. Uma forma comum de pensar este sentimento éafirmar que ele é simplesmente desencadeado pela opinião de outrem.

A vergonha é a não-aceitação decorrente do processo psicológico de ser pego em flagrante e fora dos padrões aceitos e valorizados. A presença do outro, insinuada como testemunha, fiscal, juiz, avaliador, é determinante do sentir vergonha. As pessoas não sentem vergonha por estarem fora dos padrões, mas quando são flagradas. A estruturação da vivência de vergonha vai depender dos processos relacionais de seus contextos. A vergonha pode ser estruturada no nível corporal, no social e no existencial. A gente tem aquele sentimento de medo, né, de fazer, que fica com vergonha pra olhar pra cara do médico depois. (Lucy, 38 anos). Não se trata de uma dor ou de um simples incômodo em outras partes do corpo, trata-se dela [mulher] diante do outro ser humano que, dependendo da forma de interação, pode instigar diferentes sentimentos em relação ao próprio exame ${ }^{31}$. 


\section{0 nervosismo e o medo}

0 nervosismo e o medo estiveram presentes nas mulheres, antes, durante e após a realização do exame, como expressa a fal a: Toda vida que eu vou fazer prevenção, eu fico nervosa. Pra mim, eu acho que dói. [...] e quando me dei to na mesa, ou na cama, ai meu Deus! Aí é que eu fico nervosa. (Lenita, 49 anos).

Pode-se dizer que o medo é um sentimento de inquietação diante de um perigo real ou imaginário. M yra \& Lopez ${ }^{32}$ compreendem que 0 medo age como sinal condicionante e antecipador de sofrimento, caso tome proporções altas. 0 medo é desencadeado a partir de uma situação concreta, presente emaléfica. Alguns relatos evidenciaram que o medo está relacionado ao exame, propriamente dito, e à expectativa de terem algum problema de saúde: Porque tenho medo daqueles ferros. Quando eu vejo aqueles ferros, ai meu Deus! Morro de medo. (Lenita, 49 anos). Porque a gente tem medo do resultado, né? Podedá algum problema. (Cícera, 29 anos). Compreendemos por que o medo existe, pois é lastimável e sofredor saber que se está com alguma doença, principalmentesefor câncer cérvico-uterino. Para Sontag ${ }^{33}$, o câncer nunca foi visto senão como um flagelo; metaforicamente, a barbáriedentro do organismo.

Entretanto, no momento em que o profissional de saúde relata que está tudo bem, a sensação de desconforto, medo, apreensão enervosismo imediatamente dá lugar à sensação de alívio e de bem-estar, embora, nem sempre, o diagnóstico imediato seja completamente seguro. É tanto que a mulher destacou: a gente quer fazer 0 examepra saber setá sentindo alguma coisa. Quando volta [quando termina o exame] já sai aliviada [...] Quando a doutora diz que tá tudo bem. (Beth, 24 anos).

A exposição da mulher ao profissional desaúdedo sexo masculino também foi motivo de constrangimento e até de impedimento para realização do exame. No começo, eu fiquei com medo de fazer, né? Porque homem a gente sempretem medo de fazer. A gente tem vergonha [...] (Lucy, 38 anos). Outrosdepoimentos que reforçam o pressuposto: M ary (18 anos) afirma ter vergonha de ficar com as pernas abertas pro médico. Porque a primeira vez que um homem, além do meu marido, tinha me visto despida [...] Deu vergonha. E o de Iracy (32 anos): [...] Eu prefiro nem fazer. Como nosso sistema de saúde está voltado para a vinculação da clientela à unidade de saúdemais próxima, a mulher tem pouca oportunidade ou nenhuma de escolher o profissional de saúde.
Para algumas delas, a preferência pelo profissional do sexo feminino diz respeito, também, ao modelo de educação que receberam, no qual as zonas erógenas não deveriam ser tocadas nem examinadas por outra pessoa, senão pelo marido, mesmo que essa pessoa fosse um médico, por se sentirem envergonhadas, desconfortáveis e pouco à vontade. Isto remete à discussão sobre pudor, como barreira na esfera da subjetividade, de mensuração difícil, que dificulta a exposição do corpo a um profissional do sexo masculino. Há quem procure amenizar, entretanto, 0 estresse de ser atendida por um homem. M esmo assim nervosa, eu venho fazer a minha prevenção [...] Porque a gente tem que ter o compromisso de fazer, ou com médico, ou doutora, tem que fazer a prevenção. (Lucy, 38 anos). Apesar de a entrevistada afirmar que não se importa com o sexo do profissional, não significa dizer que ela não tenha preferência.

\section{Acessibilidade ao serviço}

Além das dificuldades intrínsecas de cada muIher, registramos outras que interferem no seu acesso aos serviços de saúde: o exame como empecilho para as "obrigações sexuais" da mulher para com o marido, ao não permitirem que elas fizessem a prevenção, reafirmando a noção de poder do homem sobre a vida da mulher. Consuelo (27 anos), há quatro anos sem fazer o exame, afirmou: Ele diz assim: tu vai passar quanto tempo sem poder fazer amor [... ] Ah! Eu vou arrumar outra. 0 baixo poder aquisitivo, observado a partir das conversas e, principalmente, das queixas de uma vida sacrificada, cheia de dificuldades até para se ausentar de casa; como a menina ficou em casa e não tinha quem ficasse com ela. Aí eu encontrei uma menina e dei $R \$ 3,00$ a ela para ela ficar com a minha menina, enquanto eu fazia o exame hoje. (Chica, 35 anos).

Muitas mulheres vão à consulta acompanhadas por seus filhos pequenos; alguns ainda de colo, por não terem com quem deixá-los, ou levam os maiores, para Ihes fazerem companhia. Tal circunstância reafirma a questão de gênero como um sistema de classificação social que organiza contrastivamente os atributos masculinos e femininos em nossa sociedade, onde o cuidado e a educação das crianças são atribuições específicas das mulheres ${ }^{21}$. Por conseguinte, 0 acesso inadequado ao atendimento básico pode desestimular as mulheres a procurarem os serviços de saúde; estas, por vezes, têm de pernoitar nas filas e/ou ter amizades para 
conseguir atendimento ${ }^{34}$. Outros sentimentos emergiram, em relação à organização dos serviços, como o descontentamento e a indignação pela demora no atendimento ou agendamento do exame; pela fal ta de material para realização do exame; e pelo número insuficiente de vagas, como descrevem os relatos: $\mathrm{H}$ oje, por exemplo, a minha consulta [exame de prevenção] tá marcada, aí [... ] Não aconteceu [...] Porque faltava material [...] 0 certo é [...] Eles avisassem pra gente não vir e ficar esperando até agora? Eu fico pensando nisso [...] Venho com esse nervoso [...] Eu penso que todo mundo vem nervosa fazer esse exame [...] Que pena que eu não fiz o exame. (Maria, 40 anos).

Acerca disso, Batista ${ }^{35}$ ressalta que os serviços de saúde estão organizados obedecendo à lógica do Programa Saúde da Família; porém, no M unicípio, trata-se de um programa verticalizado, focalizado excludente.

Ora, se a mulher já chega à unidade com representações negativas, das quais sobressaem 0 medo, a vergonha e o nervosismo, e não consegue ser atendida, é possível imaginar o quão maléfica é a repercussão desse momento para essas pessoas. Se algumas já sofrem, por antecipação, as surpresas que esse exame pode trazer, além do constrangimento de se despirem para estranhos, uma negação do atendimento pode desencadear situações de estresse, revolta e/ou desânimo, interferindo no conjunto de opiniões a respeito do exame de prevenção e ensejando conflitos nas mulheres.

Visando a superar a fragmentação das políticas e programas de saúde, o M inistério da Saúde está propondo o "Pacto pela Saúde", em três dimensões: Pacto pela Vida, em D efesa do SUS e Pacto de Gestão. 0 "Pacto pela Saúde" propõe, entre outras, a estruturação de uma rede solidária eregionalizada de ações eserviços que qual ifique o processo de gestão ${ }^{36}$.

\section{Desinformação sobre prevenção}

Sob este aspecto, a maioria das mulheres pesquisadas demonstra desinformação sobre o exame de prevenção, suas etapas e nuanças. Essa situação denota desigual dade entre o ser e o saber. Geralmente, essas mulheres chegam ao Centro com pouca informação do "ritual" acerca do exame e, ao se colocar diante do profissional, a mulher sente-se objeto de inspeção e associa a exposição da genitália à sexualidade; daí o sentimento de vergonha em relação a ela (sexualida- de) ${ }^{37}$. Eu fiquei [nervosa], porque nunca tinha feito [o exame]. Eu fiquei porque não sabia que era assim. (Dadá, 61 anos). A falta de informação em muitos casos funciona como indutor de nervosismo, ansiedade e medo, conforme explicitado nos depoimentos, independentemente da idade e do nível de instrução.

\section{Considerações finais}

0 estudo revelou que, mesmo superando dificuldades, via de regra, as mulheres procuram os serviços de saúde para se submeterem ao exame de prevenção do câncer cérvico-uterino. A motivação para realizar esse exame está vinculada ao aparecimento de sintomas, ao prazer de se cuidar rotineiramente e/ou na preocupação com sua condição de saúde, pois reconhecem, em seus companheiros, risco em potencial para 0 adoecimento.

Ficou evidenteque a mulher percebe o exame como uma circunstância envolta de sensações relacionadas, na maioria das vezes, à vergonha, ao medo de doer, à positividade do resultado e ao desconhecimento do ritual do exame. 0 nervosismo também foi relatado, principalmente, durante a espera do resultado do exame. Esse fato sugere que, apesar do conhecimento superficial sobre o câncer, algumas mulheres sabem que, a partir desse exame, podeser detectada uma doença maligna, e, por conseguinte, uma mudança de vida.

As mulheres vivenciam em seu cotidiano situações que dificultam seu acesso ao exame de prevenção. A relutância em procurar atendimento esteve relacionada, entre outros, aos seguintes impedimentos: pudor, pela exposição de seu corpo a um (a) estranho (a); preconceito do companheiro; responsabilidade sobre o cuidado com as crianças e baixo poder aquisitivo, que impede pagar alguém para ficar com as crianças pequenas; a informação de que seriam atendidas por um profissional do sexo masculino; o medo do resultado positivo para câncer; e a desinformação sobre o exame.

$\mathrm{N}$ a dinâmica do exame, parte das mulheres sente-se envergonhada e desconfortável por ter a genitália exposta e manipulada por um profissional, revelando o quanto a mulher, na maioria, independentemente do grau de instrução, da idade e da origem social, ainda reluta em considerar um exame desse nível como procedimento natural.

A falta de educação sexual nas famílias e na 
escola é uma das causas prováveis do pouco conhecimento sobre o corpo eacerca da sexualidade. Neste sentido, apreendemos a noção de que os profissionais de saúde nem sempre estão preparados para lidar com essas questões.

Evidenciamos o fato de que foram reveladas preocupações diferentes em relação ao cuidado com o corpo, não achando necessário para al gumas e representando maior preocupação para outras, sugerindo provavelmente, quedependendo da consciência da mulher, a decisão de fazer voluntariamente este exame estaria ligada ao seu próprio prazer de ser mulher. Desse modo, a de- sinformação não seria a única justificativa para a (não) busca do exame.

Por esta razão, consideramos relevantea educação permanente em saúde, atividades educativas junto às mulheres, parcerias entre os serviços de saúde e universidades e/ou escolas e/ou organizações que lidem com essa temática eque possam promover a atenção para a prevenção do câncer cérvico-uterino. Que o governo priorize campanhas de esclarecimento acerca desse câncer, sobretudo, na mídia televisiva, que abrangeriaigualmente os cônjuges, quenem semprecompreendem a necessidade dessa prevenção.

\section{Colaboradores}

LM Duavy trabalhou na coleta e análise dos dados e preparo inicial dos manuscritos, FLR Batista, na redação e discussão teórica, M SB Jorge orientou na interpretação dos dados e trabal hou na aprovação da versão a ser publicada e JBF Santos orientou no delineamento e interpretação dos dados.

\section{Referências}

1. Brasil. Ministério da Saúde. Incidência de câncer no Brasil: estimativa/2005. Brasília: Instituto Nacional do Câncer. 2004 [acessado 2004 Dez 06]; [cerca de 15 p.]. Disponível em: http://www.inca.gov. br/estimativa2005

2. Brasil. M inistério da Saúde. Instituto $\mathrm{N}$ acional do Câncer. Falando sobre o câncer do colo do útero. Rio de Janeiro: INCA; 2002.

3. SM S. Secretaria de Saúde de Fortaleza. Resgate histórico da saúde de Fortaleza 1990-2003. Fortaleza: SM S; 2004. [M imeo]

4. Costa AM. Desenvolvimento e implementação do Programa de Assistência Integral à Saúde da M uIher. In: Giffin K, Costa SH, organizadoras. Questões da saúde reprodutiva. Rio de Janeiro: Fiocruz; 1999. p. 319-35.

5. Canesqui AM. A saúde da mulher em debate. Revista Saúde em Debate 1984; (15-16): 29-36. 
6. Osis MID. Atenção integral à saúde da mulher, 0 conceito e o programa: história de uma intervenção [dissertação]. Campinas (SP): Universidade Estadual de Campinas; 1994.

7. Alvarez SE. Engendering Democracy in Brasil. Women's M ovement Intransition politics. New Jersey: Princeton University Press; 1990.

8. Formiga JFN. Políticas de saúde reprodutiva no Brasil: uma análise do PAISM . In: Galvão L, Diaz J, organizadores. Saúde sexual e reprodutiva no Brasil: dilemas e desafios. São Paulo: Hucitec; Population Council; 1999. p. 151-79.

9. Brasil. Ministério da Saúde. Assistência integral à saúde da mulher: bases de ação programática. Brasília: Centro de Documentação; 1984.

10. Correia SO, Piola SF. Balanço 1998 - 2002: aspectos estratégicos, programáticos e financeiros. Brasília: M S; 2003.

11. Brasil. M inistério da Saúde. Secretaria de Atenção à Saúde. Departamento de Ações Programáticas Estratégicas. Política N acional deA tenção Integral à Saúde da Mulher: princípios e diretrizes. Brasília: MS; 2004.

12. Gonçalves R, M erighi MAB. Transformar-se enquanto mulher: um estudo de caso sobre a vivência do período pós-parto. In: M eringhi, M AB, Praça NS, organizadores. Abordagens teórico-metodológicas qualitativas. Rio de Janeiro: Guanabara Koogan; 2003. p. 121-33.

13. Triviños ANS. Introdução à pesquisa em Ciências Sociais. 2a ed. São Paulo: Atlas; 1990.

14. Polit DF, Hungler BP. Nursing Research: principles and M ethods. $6^{\text {th }}$ ed. Philadelphia: Lippincott; 1999.

15. Brasil. Ministério da Saúde. Conselho Nacional de Saúde. Resolução no 196, de 10 de outubro de 1996.

16. Bardin L. Análise de conteúdo. Lisboa: Edições 70; 1977.

17. Rodrigues DP, Fernandes AFC, Silva RM . Percepção de algumas mulheres sobre 0 exame Papanicolau. Rev Enferm [on line] $2001 \mathrm{Abr}$ [acessado 2003 Out 03]; [cerca de 5 p.]. Disponível em http://bases.bireme. $\mathrm{br} / \mathrm{cgi}$-bin/wxislind.exe/iah/on line

18. Maluhy MA. A percepção da mulher frente ao exame ginecológico: um olhar a partir da profissional da equipe de enfermagem [dissertação]. Rio de Janeiro (RJ): Escola de Enfermagem Anna Nery; 2001.

19. Boff L. A águia e a galinha: uma metáfora da condição humana. 29a ed. Petrópolis: Vozes; 1999.

20. Gois MMS. Aspectos históricos e sociais da anticoncepção. Reproduo 1991; 6(3):119-24.

21. Bampi MAM. Poder, opressão e dependência na construção da subjetividade feminina. In: Bello JLPP. Pedagogia em foco. [internet] 1999 [acessado 2003 N ov 05]. Disponível em: http://www.pedagogia em foco.pro.br/mulher01.htm

22. Foucault M. História da Sexualidade I: a vontade de saber. 12a ed. Rio de Janeiro: Graal; 1997.
23. Brandão ER e Heilborn ML. Sexualidade e gravidez na adolescência entre jovens de camadas médias do Rio de Janeiro, Brasil. Cad Saúde Pública [periódico na internet]. 2006 jul [acessado 2006 Jul 15];22(7):[cerca de 15 p.]. Disponível em: http:// www.scielosp.org/scielo. $\mathrm{ph} p=\$ 0102-311 \mathrm{X}$

24. Laplanche J. Vida e morte em psicanálise. Porto Ale gre: Artes M édicas; 1995.

25. Reis AP. Inscrições corporais e menopausa: signos da meia-idade numa perspectiva antropológica. In: Barbosa RM, Aquino EM L, Heilborn ML, Berquó $E$, organizadores. Interfaces: gênero, sexualidade e saúde reprodutiva. Campinas: Editora da Unicamp; 2002. p. 207-43.

26. Freud S. Sexualidade feminina. In: Edição Standard Brasileira das obras completas. Rio de Janeiro: Imago; 1974.

27. Villela WV. Num país tropical, do sexo que se faz ao sexo do qual fala. In: Galvão L, Díaz J, organizadores. Saúde sexual e reprodutiva no Brasil: dilemas e desafios. São Paulo: Fiocruz; 1999. p. 310-23.

28. Diamantino EMV, et al. Aspectos básicos da sexualidade humana na parte clínica. Parte I. Feminina 1993; 21(10):1016-29.

29. La Taille I. Vergonha, a ferida moral. 2ª ed. Petrópolis: Vozes; 2002.

30. Darwin C. L'expression des émotions chez I'homme et les animaux. Bruxelle: Complexe; 1981.

31. Salciedo-Barrientos DM, Egry EY. Mulher e saúde: uma visão de gênero na percepção das usuárias acerca do exame ginecológico. [online] Jan - jun 1999 [acessado 2003 Out 03]. Disponível em: http:/ bireme.Br./cgibin/wxislind.exe/iah/online/

32. M yra y Lopez E. Os quatro gigantes da alma: o medo, a ira, o dever, o amor. Rio de Janeiro: José Olímpio; 1996.

33. Sontag S. A doença como metáfora. Rio de Janeiro: Edições Graal; 1984.

34. Carvalho GM. Enfermagem em ginecologia. São Paulo: EPU; 1996.

35. Batista FLR. Atenção básica no município de Fortaleza. In: Costa LFA, Lessa APG, organizadoras. 0 serviço social no Sistema Único de Saúde. Fortaleza: EdUECE; 2003. p. 51-63.

36. Brasil. M inistério da Saúde. Secretaria Executiva. Departamento de Apoio à Descentralização. Coordenação-Geral de Apoio à Gestão Descentralizada. Diretrizes operacionais dos pactos pela vida, em defesa do SUS e de gestão. Braślia: MS; 2006.

37. Lopes MJM, Meyer DE, Waldow VR. Gênero e saúde. Porto Alegre: Artes M édicas; 1996.

Artigo apresentado em 28/12/2005

Aprovado em 26/06/2006

Versão final apresentada em 02/10/2006 